\title{
Bilateral Total Aplasia of Paranasal Sinuses: A Rare Case Report
}

\author{
${ }^{1}$ Ankita Joshi, ${ }^{2}$ Chinmay Sundarray, ${ }^{3}$ Krishna Arpita Sahoo
}

\begin{abstract}
Paranasal sinus anatomical anomalies with unknown etiology are common. Paranasal sinus-related diseases are associated with so high rate of morbidities, it becomes essential to identify the structure and pathophysiology of the paranasal sinuses. Computed tomography (CT) is a valuable tool in displaying its anatomy, any anatomic variations and diseases. As paranasal sinus development is a complex and long-lasting process, there are great structural variations between individuals. Maxillary and/or frontal sinus aplasia or hypoplasia are more common than the other types. Several degrees and combinations of aplasias and hypoplasias have been reported; however, there is only two case of total paranasal sinus aplasia in the literature. Here, we present the third case of total paranasal sinus aplasia, and the first ever case reported from India.
\end{abstract}

Keywords: Functions of the paranasal sinuses, Paranasal sinus development, Role of CT.

How to cite this article: Joshi A, Sundarray C, Sahoo KA. Bilateral Total Aplasia of Paranasal Sinuses: A Rare Case Report. Clin Rhinol An Int J 2015;8(3):124-126.

Source of support: Nil

Conflict of interest: None

\section{INTRODUCTION}

Paranasal sinuses are empty spaces located within the skull bones around the nasal cavity. Their development and final shape show great variations, and even identical twins may have different configurations. Paranasal sinuses are prone to a great diversity of anomalies. Aplasia of the frontal sinus is a relatively common phenomenon and may be accompanied with hypoplasia of the maxillary sinus, but combined aplasia or underdevelopment of all the paranasal sinuses is unusual. These developmental pathologies may be misdiagnosed as sinusitis or neoplasm. It is also crucial to clarify the anatomic details of the paranasal sinuses for correct diagnosis of diseases and for appropriate surgical planning before any surgical

\footnotetext{
${ }^{1}$ Postgraduate, ${ }^{2}$ Assistant Professor, ${ }^{3}$ Senior Resident

${ }^{1-3}$ Department of ENT, SCB Medical College, Cuttack, Odisha India
}

Corresponding Author: Ankita Joshi, Postgraduate, Department of ENT, SCB Medical College, Cuttack, Odisha, India Phone: 08763694754, e-mail: drjoshiankita@gmail.com procedures such as functional endoscopic sinus surgery (FESS) and transsphenoidal hypophysectomy. Computed tomography (CT) is an excellent imaging technique that is used to map sinus anatomy. A variety of paranasal sinus anomalies have been described in the literature but, to our knowledge using Google search PubMed, we found only two cases of total paranasal sinus aplasia being reported. This article presents the third case of total paranasal sinus aplasia.

\section{CASE REPORT}

A 15-year-old Hindu male patient, presented to ENT OPD with the complaints of chronic frequent bilateral headache associated with facial fullness and frequent throat clearing habit. He gave no previous history of recurrent nasal allergies, nasal surgery, or facial trauma or irradiation or systemic diseases affecting the skeletal system such as Paget's disease, osteopetrosis, or fibrous dysplasia. No other abnormality was found on laboratory examinations, including cystic fibrosis. However, he gave a treatment history for sinusitis several times without any relief.

Physical examination did not reveal any gross pathological sign. His facial appearance was not normal. His malar prominence was absent. The nasal cavities seemed normal except, deviated nasal septum toward left side. Computed tomography scan of PNS was obtained with 5 $\mathrm{mm}$-slice thickness. The CT scans showed deviated nasal septum toward the left side and all the three turbinates were small and rudimentary. Further, it revealed a total lack of development or pneumatization of all the paranasal sinuses (Figs 1 and 2). However, no other craniofacial anomaly was observed.

\section{DISCUSSION AND CONCLUSION}

The paranasal sinuses begin their development as an evagination of the mucosa from the nasal cavities during the third and fourth fetal months. ${ }^{7}$ They undergo major expansion after birth, along with the development of the facial cranium and teeth. At birth rudimentary maxillary and ethmoid sinuses are present but sphenoid and frontal sinuses are undeveloped. The maxillary sinus extends laterally past the infraorbital canal by the age of 4 years and reaches the maxillary bone by the age of 9 years. At 

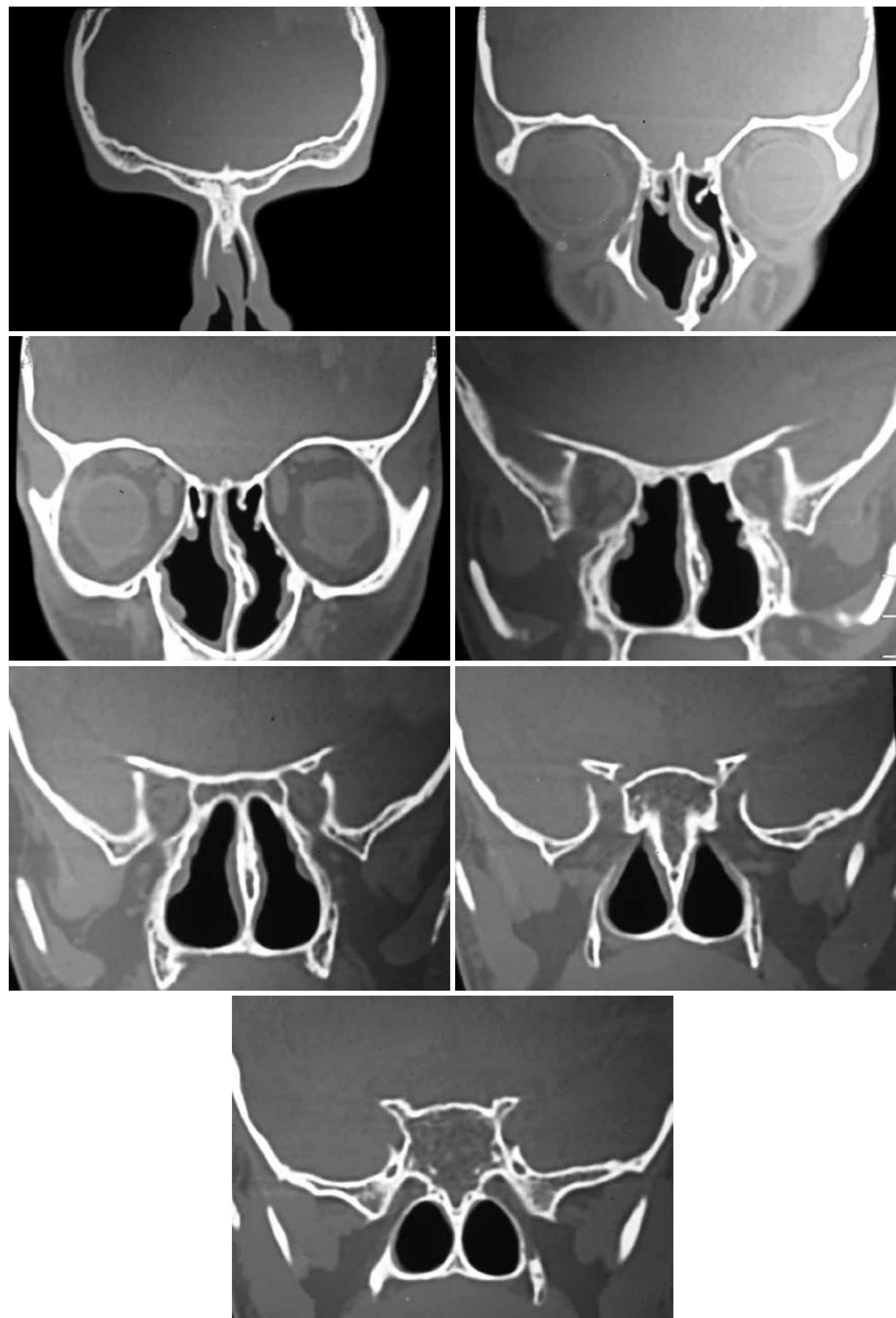

Fig. 1: Computed tomography scan of PNS coronal view 


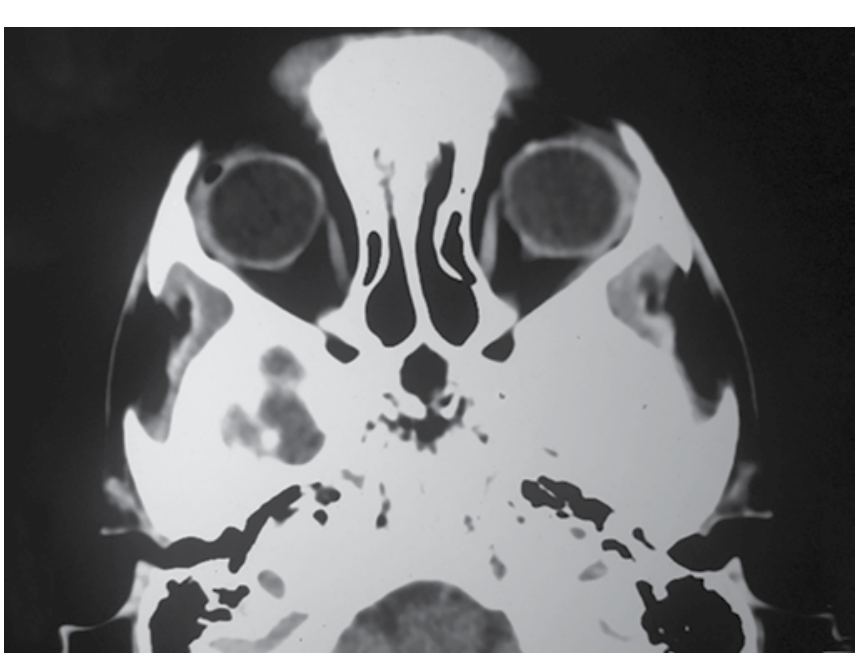

Fig. 2: Computed tomography scan of PNS axial view

birth, ethmoid cells are more developed anteriorly and pneumatization progresses in a posterior direction. Their growth lasts until late puberty. Pneumatization of the sphenoidal sinuses can be detected as early as 2 years of age and they reach the final size by the age of 14 years. The last paranasal sinus undergoing major expansion is the frontal sinus. Its growth starts after 2 years of age and reaches its final size after puberty.

Paranasal sinuses present with great structural variations. Aplasia of the sphenoidal sinus is extremely rare. Frontal sinus aplasia is present unilaterally in $15 \%$ and bilaterally in $5 \%$ of normal adults. ${ }^{8}$ Maxillary sinus aplasia is extremely rare, whereas maxillary sinus hypoplasia is a well-known clinical entity. ${ }^{9}$ Maxillary sinus hypoplasia is reported in 1.7 to $10.4 \%$ of patients with sinonasal symptoms. ${ }^{10,11}$ To the best of our knowledge, this is the third case report of total paranasal sinus aplasia in the English language literature and the first ever case reported in India. While dealing with paranasal sinus disease, paranasal sinus aplasia and hypoplasia should be kept in mind because:

First, the prevalence of frontal and sphenoidal sinus aplasia or hypoplasia have been shown to be higher in patients with cystic fibrosis or primary ciliary dyskinesia. So, in a patient with paranasal sinus hypoplasia and aplasia, we should consider and exclude primary ciliary dyskinesia and cystic fibrosis. Second, paranasal sinus aplasia and hypoplasia may lead to misdiagnosis of infections or mass lesions. These patients may be treated for months with the diagnosis of chronic sinusitis if we rely only on the routine X-rays. In suspicious cases, CT should be performed. Computed tomography reveals excellent detailed anatomy of the paranasal sinuses. ${ }^{1-4}$ Third, paranasal sinus aeration should be considered during endoscopic sinus surgeries to avoid possible complications and to perform appropriate surgeries.

Kandogan et al reported a case with combined aplasia of sphenoid, frontal, and maxillary sinuses accompanied by ethmoid sinus hypoplasia in $2012{ }^{7}$

Celebi et al reported total aplasia of PNS in 2012. ${ }^{5}$ Hakan Korkmaz et al Reported total aplasia of PNS in $2013 .{ }^{6}$

Concluding, we have to be aware of any of these rare morphological alternatives while treating sinus pathology to reach correct diagnosis.

\section{REFERENCES}

1. Chen JC, Ho CY. The significance of computed tomographic findings in the diagnosis of fungus ball in the paranasal sinuses. Am J Rhinol Allergy 2012;26:117-119.

2. Hwang $\mathrm{SH}$, Joo $\mathrm{YH}$, Seo JH, et al. Three-dimensional computed tomography analysis to help define an endoscopic endonasal approach of the pterygopalatine fossa. Am J Rhinol Allergy 2011;25:346-350.

3. Al-qudah MA. Anatomical variations in sinonasal region: a computer tomography (CT) study. J Med J 2010;44:90-97.

4. Leung R, Chaung K, Kelly JL, Chandra RK. Advancements in computed tomography management of chronic rhinosinusitis. Am J Rhinol Allergy 2011;25:299-302.

5. Celebi S, Taskin U, Altin F, Ozkul MH. Bilateral aplasia of paranasal sinuses. Eur Arch Otorhinolaryngol 2012 Mar; 269(3):1055-1057.

6. Korkmaz H, Korkmaz M. Total aplasia of the paranasal sinuses. Allergy Rhinol 2013;4:e105-e109.

7. Kandogan T, Dalgic A, Mollamehmetoglu H, Esen O. Combined aplasia of sphenoid, frontal, and maxillary sinuses with hypoplasia of the ethmoid sinus. Iran Red Cres Med J 2012;15(1):13-14.

8. Scuderi AJ, Harnsberger HR, Boyer RS. Pneumatization of the paranasal sinuses: normal features of importance to the accurate interpretation of CT scans and MR images. Am J Roentgenol 1993;160:1101-1104.

9. Lawson W, Patel ZM, Lin FY. The development and pathologic processes that influence maxillary sinus pneumatization. Anat Rec 2008;291:1554-1563.

10. Karmody CS, Carter B, Vincent ME. Developmental anomalies of the maxillary sinus. Trans Sect Otolaryngol Am Acad Ophthalmol Otolaryngol 1977;84:723-728.

11. Bassiouny A, Newlands WJ, Ali H, Zaki Y. Maxillary sinus hypoplasia and superior orbital fissure asymmetry. Laryngoscope 1982;92:441-448. 